\title{
Osteopetrosis in two siblings: two case reports
}

\author{
Satish Yadav ${ }^{*}$, Shiv Chalise', Shipra Chaudhary', Gauri Shankar Shah', Mukesh Kumar Gupta \\ and Om Prakash Mishra ${ }^{3}$
}

\begin{abstract}
Background: Osteopetrosis is a rare inherited metabolic bone disorder characterized by extensive sclerosis of skeletons, visual and hearing impairment, hepatosplenomegaly and anemia. It has two major clinical forms: the autosomal dominant adult (benign) form is associated with milder symptoms often appearing in later childhood and adulthood whereas the autosomal recessive infantile (malignant) form has severe presentations appearing in very early childhood, if untreated, is typically fatal during infancy or early childhood. A rare autosomal recessive (intermediate) form is present during childhood with some signs and symptoms of malignant osteopetrosis. Diagnosis is mainly based on clinical and typical generalized increase in bone density.
\end{abstract}

Case presentation: The two siblings of Indo-Aryan ethnicity, aged five and 8 years, were admitted with irregular low grade fever and gradually increasing abdominal mass for last 3 years. They also had history of hearing loss. On examination, the patients were found pale with poor nutritional status, short stature, frontal bossing and splenomegaly. We made a clinical diagnosis of hemolytic anemia and investigated accordingly. Peripheral Blood Smear was suggestive of leucoerythroblastic picture in both the siblings. We extended our investigations and radiological survey revealed generalized increase in bone density which was consistent with osteopetrosis.

Conclusion: Osteopetrosis is a rare disease transmitted by autosomal dominant or recessive inheritance having variable penetrance. We report here milder form of disease in the two siblings having typical clinical features in the form of anemia, hepatosplenomegaly and hearing loss. Diagnosis was confirmed by typical generalized increase in bone density in both the patients.

Keywords: Osteopetrosis, Deafness, Radiological appearance

\section{Background}

The term osteopetrosis is derived from the Greek 'osteo' meaning bone and 'petros', for stone. It is also known as 'marble bone disease' and 'Albers-Schönberg disease', after the German radiologist reported first description of the condition in 1904 [1]. This disorder includes impaired osteoclast function and marked increase in generalized bone density.

The estimated prevalence of osteopetrosis is 1 in $100,000-500,000$ births [2]. It is present as two major clinical forms-the autosomal dominant adult (benign)

\footnotetext{
*Correspondence: doctorsat_99@hotmail.com

1 Department of Pediatrics and Adolescent Medicine, B. P. Koirala Institute

of Health Sciences, Dharan, Nepal

Full list of author information is available at the end of the article
}

form is associated with a very few or no symptoms and the autosomal recessive infantile (malignant) form is typically fatal during infancy or early childhood, if left untreated. Another milder recessive (intermediate) disease has less severe presentation [3]. This is also presents in milder form due to deficiency of carbonic anhydrase II enzyme in some patients.

\section{Case presentation}

The two siblings (both males) of Indo-Aryan ethnicity, aged 5 and 8 years, were admitted to the Department of Pediatrics and adolescent medicine with history of irregular low grade fever and gradually increasing mass in the abdomen for the last 3 years. They had history of hearing loss. There was no history of previous blood transfusion, 

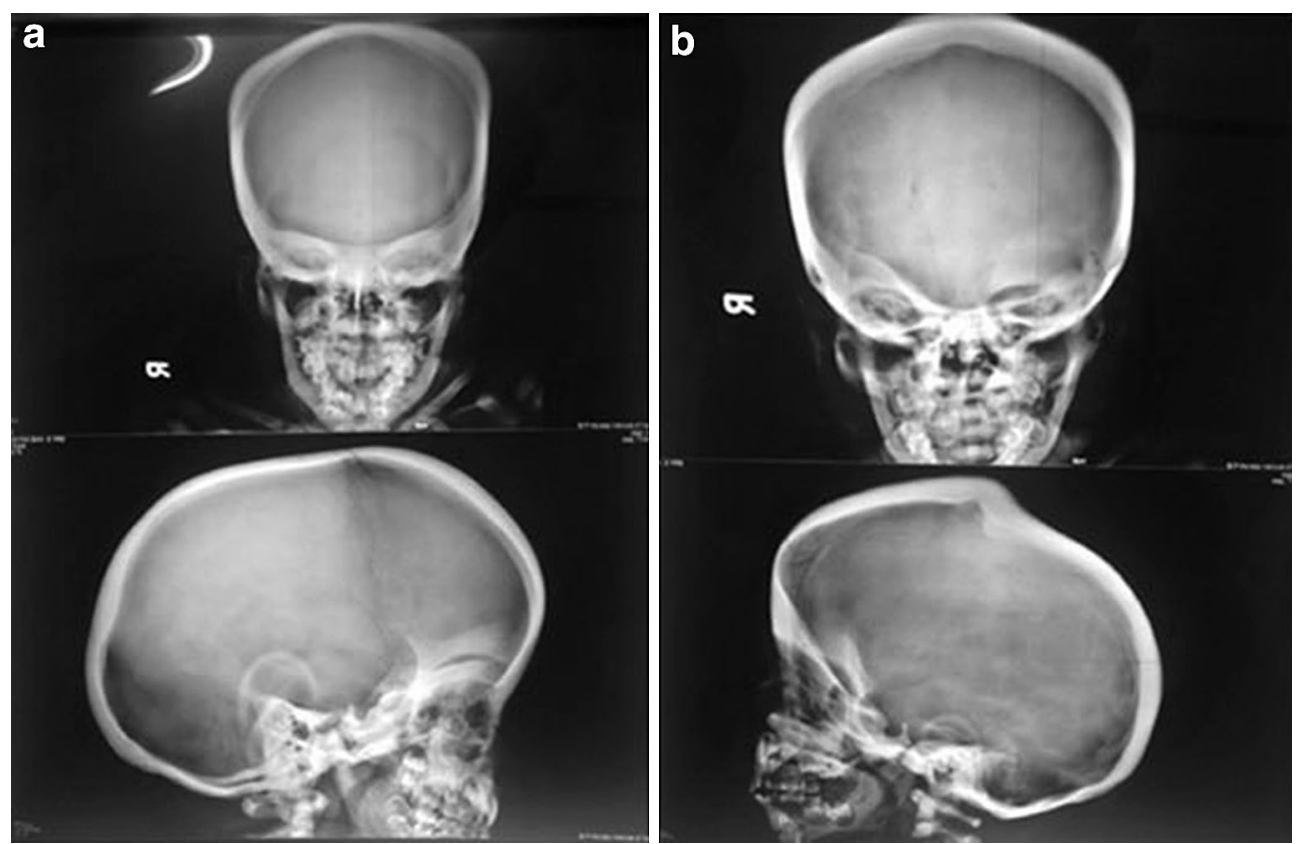

Fig. 1 Calvarial thickening with diffused increase in density of the skull bones with poor development of sinuses (a 5 years, $\mathbf{b} 8$ years)

family history of similar disease, consanguinity or any hematological disease and vision loss. Antenatal and natal periods were uneventful. There was another sibling who was 12 years old and healthy.

On examination, the patients were found to be moderately pale with poor nutritional status, short stature, frontal bossing and malformed craniofacial appearance. The younger sibling had splenomegaly of $10 \mathrm{~cm}$ below left sub-costal margin in its axis but no hepatomegaly. The older sibling had both hepatomegaly of $3 \mathrm{~cm}$ and splenomegaly of $8 \mathrm{~cm}$. Brain stem evoked response audiometry revealed hearing loss in both the patients. Ophthalmological examination was normal except nystagmus in the younger sibling.

Hemogram revealed anemia in both the siblings. Hemoglobin levels were $7.5 \mathrm{gm} / \mathrm{dl}$ in younger and $5.6 \mathrm{gm} / \mathrm{dl}$ in older sibling (ref range: $11.5-13.5 \mathrm{gm} / \mathrm{dl}$ ). Peripheral blood smear was suggestive of leucoerythroblastic picture. Other laboratory investigations yielded the following: serum total calcium 8.8 and $9.1 \mathrm{mg} / \mathrm{dl}$ (ref range: $8.7-10.3 \mathrm{mg} / \mathrm{dl}$ ), phosphorous 4.3 and $4.5 \mathrm{mg}$ / dl (ref range: $3.2-6.3 \mathrm{mg} / \mathrm{dl}$ ) and alkaline phosphatase were 235 and $345 \mathrm{U} / \mathrm{L}$ (ref range 86-315 U/L) respectively in younger and older siblings. Malaria and Kala azar were ruled out by serological test as the patients were from endemic zone. The exact cause of irregular low grade fever could not be elucidated except urine routine microscopy showed 5-7 white blood cell which was treated with oral antibiotic. On further visit, both the siblings were afebrile.

Radiological features of both the siblings revealed calvarial thickening with diffused increase in density of the bones with poor development of sinuses (Fig. 1a, b). There was homogeneous increased density of bones with little differentiation between cortex and medulla in long bones and pelvis (Fig. 2a, b). X-ray of vertebrae showed sclerosis of vertebral endplates resulting in "sandwich vertebrae" appearance and increased density of ribs (Fig. 3a, b).

Treatment which was given to both the siblings was conservative and supportive in the form of blood transfusion and regular visit for ophthalmic and dental surveillance as the disease pattern was less severe type.

\section{Discussion}

Clinical manifestations of osteopetrosis are highly variable, ranging in severity from asymptomatic to fatal course. Our two sibs had clinical features consistent with mild recessive (intermediate) form of disease supported by classical radiological findings. This form is more severe than the adult form but less severe than the malignant infantile form. The main features are short stature, frontal bossing with dysmorphic craniofacial appearance, pallor, splenomegaly and hearing loss. Short stature is due to impaired longitudinal growth and dysmorphic craniofacial appearance is caused by macrocephalus and 

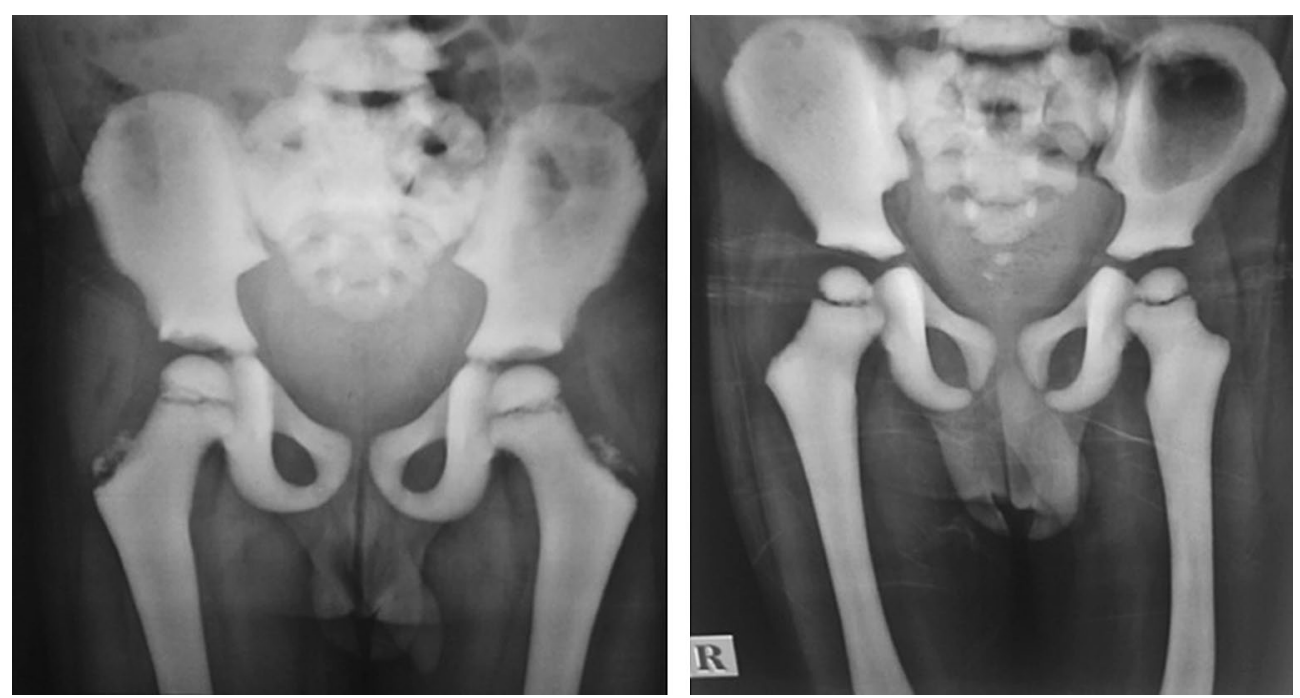

Fig. 2 Homogeneous increased density of bone with little differentiation between cortex and medulla in long bones and pelvis (a 5 years, $\mathbf{b}$ 8 years)
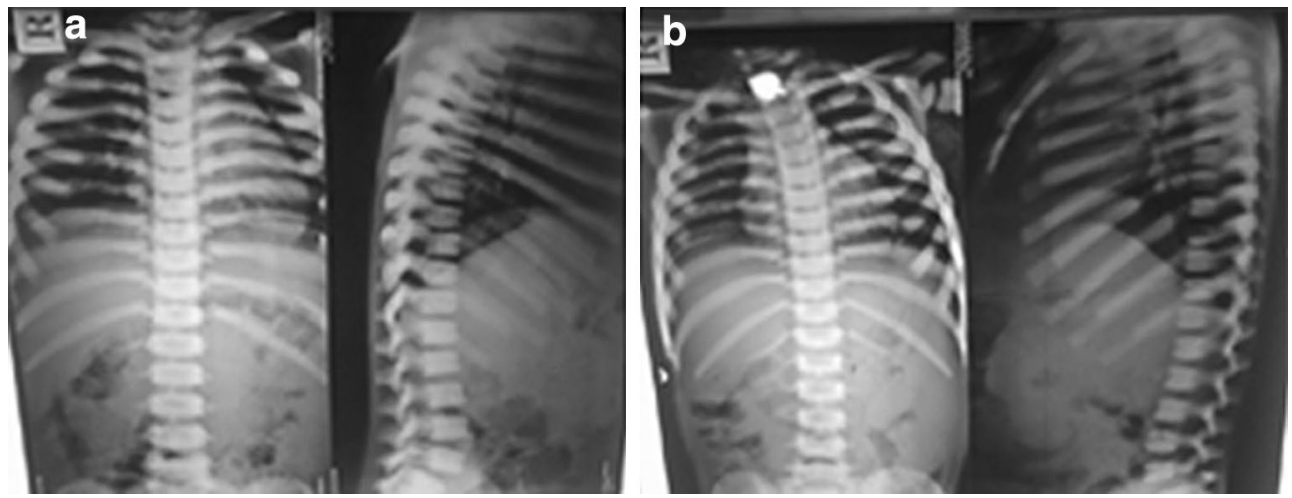

Fig. 3 Sclerosis of vertebral endplates resulting in "sandwich vertebrae" appearance and increased density of ribs (a 5 years, b 8 years)

bossing of forehead [4]. Anemia in osteopetrosis is leukoerythroblastic in type which was present in both the siblings [5].

The infantile malignant form is characterized by severe clinical features manifesting in the first few months of life. The presenting features are fractures and osteomyelitis, short stature, typical facial appearance due to macrocephaly and frontal bossing [6]. The expanding bone can narrow nerve foramina involving cranial nerves resulting in blindness, deafness, and facial palsy [7]. The abnormal expansion of bone interferes with medullary haematopoiesis resulted in life-threatening pancytopenia and extramedullary haematopoiesis which may lead to enlargement of liver and spleen. This form is fatal in majority of cases within the first 5 years of life.
The mainstay of diagnosis largely depends on the radiographic appearance of the skeleton. There are diffused osteosclerosis affecting the skull, spine, pelvis and appendicular bones, cortical thickening with medullary encroachment, poorly pneumatized paranasal sinuses and "Sandwich" appearance of vertebrae due to alternating sclerotic and radiolucent transverse metaphyseal lines [4]. There is no demarcation of cortex and medulla in the long bones.

Hematopoietic stem cell transplantation (HSCT) is the only treatment that can offer cure to such patients. HSCT using HLA identical donors results in $73 \% 5$ years disease free survival [8]. Interferon gamma $1 \mathrm{~b}$ (IFN $\gamma 1 \mathrm{~b}$ ) treatment has been tried in patients with osteopetrosis variants unresponsive to HSCT or as a bridging 
therapy to transplantation. It has been reported to result in improvement in immune function, increased bone resorption and increase in bone marrow space [9-11].

\section{Conclusion}

Though osteopetrosis is a rare disease, one can consider in children presenting with unexplained anemia and hepatosplenomegaly and radiological survey is required to confirm the diagnosis.

\section{Consent}

Written informed consent was obtained from the patients' parents for publication of this case report and any accompanying images.

\section{Abbreviations}

HSCT: hematopoietic stem cell transplantation; IFNY1b: interferon gamma 1b.

\section{Authors' contributions}

SC (Shiv Chalise) and SC (Shipra Chaudhary) participated in the initial work up of the case and helped to draft the manuscript; GSS supervised the case and helped to draft the manuscript; MKG helped in the radiological aspect of the case; OPM edited the final manuscript. All authors have read and approved the final manuscript.

\section{Author details}

${ }^{1}$ Department of Pediatrics and Adolescent Medicine, B. P. Koirala Institute of Health Sciences, Dharan, Nepal. ${ }^{2}$ Department of Radiology, B. P. Koirala Institute of Health Sciences, Dharan, Nepal. ${ }^{3}$ Department of Pediatrics, Institute of Medical Sciences, Banaras Hindu University, Varanasi, India.

\section{Competing interests}

The authors declare that they have no competing interests.

Received: 22 May 2014 Accepted: 18 January 2016

Published online: 29 January 2016

\section{References}

1. Albers-Schönberg HE. Röntgenbilder einer seltenen Knockenerkrankung. Munch Med Wochenschr. 1904;5:365-8.

2. Arumugam $E$, Harinathbabu M, Thillaigovindan R, et al. Marble bone disease: a rare bone disorder. Cureus. 2015;7(10):e339.

3. Coudert AE, de Vernejoul MC, Muraca M, Del Fattore A. Osteopetrosis and its relevance for the discovery of new functions associated with the skeleton. Int J Endocrinol. 2015;19:2015.

4. Stark Z, Savarirayan R. Osteopetrosis. Orphanet J Rare Dis. 2009;20(4):5.

5. Nayak D, Manohar C, Belurkar SV, Suvarna N. Osteopetrosis masquerading as anemia: a case report. Int J Health Sci Res. 2014;4(8):293-6.

6. Al-Tamimi YZ, Tyagi AK, Chumas PD, Crimmins DW. Patients with autosomal-recessive osteopetrosis presenting with hydrocephalus and hindbrain posterior fossa crowding. J Neurosurg Pediatr. 2008;1:103-6.

7. Dozier TS, Duncan IM, Klein AJ, Lambert PR, Key LL Jr. Otologic manifestations of malignant osteopetrosis. Otol Neurotol. 2005;26:762-6.

8. Driessen GJ, Gerritsen EJ, Fischer A, Fasth A, Hop WC, Veys P, Porta F, Cant A, Steward CG, Vossen JM, Uckan D, Friedrich W. Long-term outcome of haematopoietic stem cell transplantation in autosomal recessive osteopetrosis: an EBMT report. Bone Marrow Transplant. 2003;32:657-63.

9. Key LL Jr, Ries WL, Rodriguiz RM, Hatcher HC. Recombinant human interferon gamma therapy for osteopetrosis. J Pediatr. 1992;121(1):119-24.

10. Key LL Jr, Rodriguiz RM, Willi SM, Wright NM, Hatcher HC, Eyre DR, Cure JK, Griffin PP, Ries WL. Long-term treatment of osteopetrosis with recombinant human interferon gamma. N Engl J Med. 1995;332:1594-9.

11. Lyseng-Williamson Katherine A. Interferon $\gamma-1 \mathrm{~b}$ in chronic granulomatous disease and severe malignant osteopetrosis: a guide to its use in the USA. Drugs Ther Perspect. 2015;31:213-20.

Acknowledgements

None.

Submit your next manuscript to BioMed Central and we will help you at every step:

- We accept pre-submission inquiries

- Our selector tool helps you to find the most relevant journal

- We provide round the clock customer support

- Convenient online submission

- Thorough peer review

- Inclusion in PubMed and all major indexing services

- Maximum visibility for your research

Submit your manuscript at www.biomedcentral.com/submit 